\title{
The Potential of Red Beetroot Powder as an Athlete Supplementation According to Its Organoleptic Properties
}

\author{
Setya Rahayu ${ }^{1}$, Natalia Desy Putriningtyas ${ }^{2}$, Tandiyo Rahayu ${ }^{3}$, Mahalul Azam ${ }^{4}$, \\ Eka Yuli Astuti ${ }^{5}$ \\ \{ setyarahayu@mail.unnes.ac.id ${ }^{1}$, nataliadesy@mail.unnes.ac.id ${ }^{2}$, \\ tandiyorahayu@mail.unnes.ac.id $\left.{ }^{3}\right\}$ \\ Universitas Negeri Semarang, Semarang, Indonesia ${ }^{1,2,3,4,5}$
}

\begin{abstract}
Athletes consume dietary supplements to enhance their training capacity and performance. Beetroot (Beta vulgaris) is a vegetable that is widely used as a dietary supplement for athletes. Beetroot contains bioactive components such as betalains, vitamin $\mathrm{C}$, polyphenols, flavonoids, and saponins. Its powder form is preferable because it is easier to consume and has a longer shelf life. This study aims to compare organoleptic tests of beetroot powder, which include tastes, and color. Corn sugar is added to the beetroot powder with different composition of $5 \%, 10 \%$, and $15 \%$. Organoleptic tests were measured by the hedonic scale method. The results from the Kruskal Wallis test showed that there was a significant difference between groups $(p<0.05)$. Beetroot powder with $10 \%$ of corn sugar receives the highest acceptance among panelists and has a promising potential as a dietary supplement for the athletes.
\end{abstract}

Keywords: beetroot, organoleptic test, athlete

\section{$1 \quad$ Introduction}

Beta vulgaris $l$, commonly known as beetroot, is a vegetable from family Chenopodiaceae [1]. Beetroot is often considered as a tuber and easy to grow in almost all over the world. It can be consumed raw or roasted and often served as a soup or a part of a salad. Beetroot is a great source of betalains, polyphenols, vitamin C, carotene, flavonoid saponin, and $\mathrm{NO}^{3-}$. Vulgaxanthine I, vulgaxanthine II, indicaxanthine, betanin, prebetanin, isobetanin, and neobetanin are betalains components that also found in beetroot [2]. Betalains are pigment components of beetroot. Additionally, beetroot is also rich in phenols, including phenolic acids, flavonoids, organic acids, and inorganic acids [3]. Studies found that beetroot is a potential therapeutic agent. Beetroot supplements are reported to have potential in lowering blood pressure, preventing inflammation, and maintaining the endothelial function and hemodynamic 
[4]. Moreover, flavonoids in beetroot act as antioxidants whose activity is as high as $79.73 \mathrm{ppm}[5]$.

Antioxidant activity is related to oxidative stress. High intensity and continuous exercise can trigger the stress as well as DNA degeneration. Reactive oxygen species (ROS), which are the primary source of oxidative stress, are produced by mitochondria during exercise. Continuous and high-intensity exercises may cause an imbalance of ROS and antioxidants. 2-5\% of the oxygen used in mitochondria comes from free radicals. Exercise increases oxidative phosphorylase response that triggers free radical propagation. Catecholamines released during exercise may also trigger the production of free radicals. Other free radical compounds increased during exercises are the compounds involved in prostanoid metabolism, xanthine oxidase, $\mathrm{NAD}(\mathrm{P}) \mathrm{H}$ oxidase, and other secondary sources released as radical macrophages during tissue repair [6]. Aerobic and anaerobic exercises may increase the free radical formation and cause acute oxidative stress. The homeostatic imbalance caused by exercises depends on various risk factors such as type of exercise, intensity, duration, level of exercise, gender, age, and dietary intake [7].

Athletes are the main target of supplement consumption. Antioxidant supplementation given to athletes prevents excessive oxidative stress during exercise. If free radical exceeds antioxidant capacity, it will attack the cellular compounds. Beetroot juice supplementation is shown not to improve water polo athletes' performance, although it has ergogenic potential during dynamic apnea [8]. Beetroot powder supplementation on athletes is able to optimize response performance during submaximal run training or maximal treadmill [9]. Beetroot powder is preferred because it is easy to consume and has the feasibility of product diversification or improvement. This study aims to compare the organoleptic properties (taste, and color) of beetroot powder that has been formulated with various percentages of corn sugar. Sugar is one of the food agents used as natural preservatives and stabilizers.

\section{Methods}

This study was conducted from February to March 2020. Beetroots were obtained from organic farmers in Pakis and Ngablak Village, Magelang district, Central Java. Chosen beetroots have soft skin and long shelf life. Beetroots selection was started from removing soil, worm, or soiled part of beetroots. It was cleaned under flowing water, brushed, and sundried for a day. The blanching process using hot water is avoided to not lose the betalain content due to water dissolution. Beetroots were chopped into $1 \mathrm{~mm}$ size using bowl chopper before being crushed with a juice extractor and spray dried.

Corn sugar was then added into beetroot juice with $5 \%, 10 \%$, and $15 \%$ composition each $(w / w)$. A juice extractor would separate the juice from the pulp and the skin using a cold-pressed method and hydraulic utilization of $120 \mathrm{~kg} / \mathrm{h}$ capacity. This technology mainly operates in two steps: the pulp's production from raw materials, then 
hydraulically pressed with a vertical pressure that extracts the juice from the pulp. The final product of cold-pressed juicers is more homogenous than centrifugal juicers (common juicers).

This experiment produced three varieties of beetroot powder with corn sugar addition of 5\%,10\% and 15\%. The solution of beetroot juice and corn sugar was evaporated by a evaporator. Evaporator transforms beetroot solution by heating the solution, and the formed vapor was condensed when it passed the condenser. During this process, the beetroot solution turned into a solid form with volatile compounds and low water content. The last process to produce the beetroot powder is crystallization. Crystallization process was chosen to produce a higher purity of beetroot content in the powder.

Organoleptic properties were observed by 25 not trained panelists consisted of 15 females and 10 males at Nutrition Laboratory, Universitas Negeri Semarang. All categories in organoleptic tests were evaluated using the hedonic test scale of 1-4 (Extremely dislike to Extremely like). The tested categories were tastes, and color. Data obtained from the organoleptic test were then analyzed by the Kruskal Wallis with a p-value of 0.05 to determine significance. Ethical clearance has been obtained before the study is carried out with the number 067/KEPK/EC/2020.

\section{Results and Discussion}

Table 1. Frequency Distribution of Beetroot Powder Organoleptic Test

\begin{tabular}{|c|c|c|c|c|}
\hline \multirow{2}{*}{\multicolumn{2}{|c|}{ Groups }} & \multicolumn{3}{|c|}{ Frequency Distribution of Organoleptic Properties } \\
\hline & & Taste & Color & Overall \\
\hline \multicolumn{5}{|l|}{ A } \\
\hline- & Dislike extremely & $1(4 \%)$ & $3(12 \%)$ & $4(16 \%)$ \\
\hline- & Dislike & $14(56 \%)$ & $10(40 \%)$ & $10(40 \%)$ \\
\hline- & Like & $9(36 \%)$ & $10(40 \%)$ & $10(40 \%)$ \\
\hline- & Like extremely & $1(4 \%)$ & $2(8 \%)$ & $1(4 \%)$ \\
\hline \multicolumn{5}{|c|}{ B } \\
\hline- & Dislike extremely & $0(0 \%)$ & $0(0 \%)$ & $0(0 \%)$ \\
\hline- & Dislike & $2(8 \%)$ & $4(16 \%)$ & $2(8 \%)$ \\
\hline- & Like & $13(52 \%)$ & $13(52 \%)$ & $16(64 \%)$ \\
\hline- & Like extremely & $10(40 \%)$ & $8(32 \%)$ & $7(28 \%)$ \\
\hline \multicolumn{5}{|c|}{$x^{2}=0$} \\
\hline - & Dislike extremely & $0(0 \%)$ & $2(8 \%)$ & $0(0 \%)$ \\
\hline - & Dislike & $11(44 \%)$ & $12(48 \%)$ & $9(36 \%)$ \\
\hline - & Like & $8(32 \%)$ & $6(24 \%)$ & $7(28 \%)$ \\
\hline- & Like extremely & $6(24 \%)$ & $5(20 \%)$ & $9(36 \%)$ \\
\hline
\end{tabular}

A: beetroot powder, corn sugar 5\%; B: beetroot powder, corn sugar 10\%; C: beetroot powder, corn sugar $15 \%$

Table 1 shows that most of the panelists preferred beetroot powder with $10 \%$ corn sugar. Beetroot is a source of antioxidant with phenolic amides, flavonoids, betalains, and ferulic acid conjugates content [10]. Betalains are a bioactive pigment often found in vegetables. The family member of betalains can be categorized as betacya- 
nin - a red-violet pigment or betaxanthine - a yellow-orange pigment [4]. Betalains are water-soluble pigments that do not bind to surfaces but stain the sample. During heating, betalains will have a change color from red to yellow due to thermochemical reactions. Increased temperature allows the red pigment to change into yellow by the browning reaction. The yellow pigment is more stable in high temperatures compared to the red pigment [11]. During the spray drying process, moisture in beetroot juice is eliminated through atomization by heat. The corn sugar causes the water molecules to bind to dry beetroot powder and creates a monolayer bond with a soft texture and low water content.

Beetroot supplementation is considered a strategic plan to increase endogenous antioxidant capacity and helps to protect cells from oxidative damage. The biological environment of cells refers to the redox balance - an equilibrium between reducing (antioxidants) and oxidizing (pro-oxidants) [4], [12]. Exposure to external risk factors, namely ultraviolet radiation, xenobiotics, or endogenous synthesis derived from reactive oxygen and nitrogen species (RONS) such as inflammation, can reduce the antioxidants defense capacity and cause cellular impairment.

Beetroot consists of $87.57 \%$ water; $9.56 \%$ carbohydrate $(29.3 \%$ fiber and $70.7 \%$ sugar); $1.61 \%$ protein, $0.17 \%$ fat, and several minerals namely potassium, choline, vitamin $\mathrm{C}$, and niacin [13]. The powder form is the preferred final product of this experiment. In powder form, beetroot can be stored for a longer time, reduces the risk of biological damage and preserves pigments [1]. It is also easy to consume and increases the solubility level [14].

Table 2. Table 3. Mean Difference

\begin{tabular}{llll}
\hline Groups & \multicolumn{3}{c}{ Mean Rank } \\
\hline & Taste & Color & Overall \\
\hline A & 32.60 & 39.44 & 30.46 \\
B & 47.86 & 44.68 & 44.58 \\
C & 33.54 & 29.88 & 38.96 \\
$p$ & $0.012^{*}$ & $0.035^{*}$ & $0.048^{*}$ \\
\hline
\end{tabular}

A: beetroot powder, corn sugar 5\%; B: beetroot powder, corn sugar 10\%; C: beetroot powder, corn sugar $15 \%, p^{*}$ significant, Kruskal wallis test

Color is the main part of visual appearance, as it affects consumers' perception of food and expectation on the taste and smell of the product [15]. Table 2 displays significant differences of organoleptic test results between beetroot powder with $5 \%$, $10 \%$, and $15 \%$ of corn sugar in taste and overall appearance. Corn sugar is widely known as D-glucose or dextrose, with a chemical name of $\alpha$ - D-glucopyranose. Corn sugar comes from anhydrous or monohydrate compound that undergoes a complete hydrolysis process in acidic or enzymatic conditions. After the hydrolysis process, the refinement and the crystallization process of hydrolysate follow. Initially, corn sugar was likened to high fructose corn syrup (HFCS). HFCS consists of glucose and fructose with a ratio of 50:50 and is obtained from corn starch. Meanwhile, corn sugar is more similar to dextrose and biochemically, similar to glucose. HFCS is more similar 
to fructose and can be found in fruits. Corn sugar also acts as a binder in the beetroot powder [11].

Dextrose and glucose are carbohydrates that are easily digested. Glucose is a fastdigested carbohydrate thus is easily absorbed into blood circulation. Glucose will be oxidized through skeletal muscles during exercise. Fructose and galactose undergo different digestion processes compared to glucose. Fructose and galactose take longer to digest as they are related to hepatic metabolism. Meanwhile, fructose will be oxidized as fast as $0.38 \mathrm{~g} / \mathrm{min}$ if digested alone or combined with glucose. Meanwhile, the oxidation rate of glucose is $3.0 \mathrm{~g} / \mathrm{min}$. The glucose oxidation is also facilitated by sodium-dependent glucose cotransporter (SGLT1), which also contributes to glucose absorption through active transport past membrane brush border on small intestines. Beetroot powder with corn sugar is expected to increase the SGLT1 transport.

Further studies are recommended to evaluate beetroot powder's physical appearance, including viscosity and osmolality, and to carry out laboratory tests regarding its antioxidant contents.

\section{Conclusion}

Beetroot powder with $10 \%$ corn sugar potentially receives the highest acceptance among the panelists. Beetroot powder is a potential functional food for athletes due to its betalain content.

\section{Acknowledgments}

We would like to thank Faculty of Sport Science, Universitas Negeri Semarang, Indonesia.

\section{References}

[1] A. S. Varner, "Modeling and Optimization of the Dehydration of Beets for Use As a Value-Added Food Ingredient," p. 88, 2014.

[2] M. V. Garnacho-Castaño et al., "Effects of a single dose of beetroot juice on cycling time trial performance at ventilatory thresholds intensity in male triathletes," J. Int. Soc. Sports Nutr., vol. 15, no. 1, Oct. 2018, doi: 10.1186/s12970-018-0255-6.

[3] E. L. do Carmo et al., "Stability of spray-dried beetroot extract using oligosaccharides and whey proteins," Food Chem., vol. 249, pp. 51-59, 2018, doi: 10.1016/j.foodchem.2017.12.076.

[4] T. Clifford, G. Howatson, D. J. West, and E. J. Stevenson, "The potential benefits of red beetroot supplementation in health and disease," Nutrients, vol. 7, no. 4. MDPI AG, pp. 2801-2822, Apr. 14, 2015, doi: 10.3390/nu7042801.

[5] S. Mutiara Novatama, E. Kusumo, and D. Supartono, "Identifikasi Betasianin dan Uji Antioksidan Ekstrak Buah Bit Merah," Indo. J. Chem. Sci, vol. 5, no. 3, pp. 217-220, 2016, [Online]. Available: http://journal.unnes.ac.id/sju/index.php/ijcs. 
[6] M. L. Urso and P. M. Clarkson, "Oxidative stress, exercise, and antioxidant supplementation," Toxicology, vol. 189, no. 1-2. Elsevier Ireland Ltd, pp. 41-54, Jul. 15, 2003, doi: 10.1016/S0300-483X(03)00151-3.

[7] S. A. Guaraldo et al., "The effect of low-level laser therapy on oxidative stress and functional fitness in aged rats subjected to swimming: an aerobic exercise," Lasers Med. Sci., vol. 31, no. 5, pp. 833-840, Jul. 2016, doi: 10.1007/s10103-016-1882-2.

[8] K. L. Jonvik, J. W. Van Dijk, J. M. G. Senden, L. J. C. Van Loon, and L. B. Verdijk, "The effect of beetroot juice supplementation on dynamic apnea and intermittent sprint performance in elite female water polo players," Int. J. Sport Nutr. Exerc. Metab., vol. 28, no. 5, pp. 468-473, Sep. 2018, doi: 10.1123/ijsnem.2017-0293.

[9] J. Oskarsson and K. Mcgawley, "No individual or combined effects of caffeine and beetroot-juice supplementation during 1 submaximal or maximal running 23 ," 2018.

[10] J. L. Flueck, A. Bogdanova, S. Mettler, and C. Perret, "Is beetroot juice more effective than sodium nitrate? - The effects of equimolar nitrate dosages of nitrate-rich beetroot juice and sodium nitrate on oxygen consumption during exercise," Appl. Physiol. Nutr. Metab., pp. 1-29.

[11] S. V. Gokhale and S. S. Lele, "Dehydration of red beet root (Beta vulgaris) by hot air drying: Process optimization and mathematical modeling," Food Sci. Biotechnol., vol. 20, no. 4, pp. 955-964, 2011, doi: 10.1007/s10068-011-0132-4.

[12] J. M. Peake, K. Suzuki, and J. S. Coombes, "The influence of antioxidant supplementation on markers of inflammation and the relationship to oxidative stress after exercise," J. Nutr. Biochem., vol. 18, pp. 357-371, 2007, doi: 10.1016/j.jnutbio.2006.10.005.

[13] U. S. D. of Agriculture, "USDA National Nutrient Database for Standard Reference, Release 26," 2011. [Online]. Available: http://ndb.nal.usda.gov/.

[14] B. Singh and B. S. Hathan, "Process optimization of spray drying of beetroot Juice," $J$. Food Sci. Technol., vol. 54, no. 8, pp. 2241-2250, 2017, doi: 10.1007/s13197-017-26598.

[15] M. Kaimainen, O. Laaksonen, E. Järvenpää, M. Sandell, and R. Huopalahti, “Consumer acceptance and stability of spray dried betanin in model juices," Food Chem., vol. 187, pp. 398-406, 2015, doi: 10.1016/j.foodchem.2015.04.064. 